\title{
Malnutrition Reduces Quality of Life and Performance in Hospitalized Elderly
}

\author{
Patrizia D'Amelio ${ }^{*}$, Barbara Rosso², Giorgia Fornelli' ${ }^{1}$, Chiara Eandi', Maria T. Maniero², \\ Daniela Cobianchi², Valerio Dimonte ${ }^{3}$, Manuela Rebellato², Giovanni C. Isaia1 \\ ${ }^{1}$ Gerontology Section, Department of Medical Science, University of Torino, Torino, Italy \\ ${ }^{2}$ Gerontology Section, City of Health and Science Hospital, Torino, Italy \\ ${ }^{3}$ University of Torino, Torino, Italy \\ Email: ${ }^{*}$ patrizia.damelio@unito.it
}

Received 24 February 2014; revised 24 March 2014; accepted 10 April 2014

Copyright (C) 2014 by authors and Scientific Research Publishing Inc.

This work is licensed under the Creative Commons Attribution International License (CC BY).

http://creativecommons.org/licenses/by/4.0/

(c) (i) Open Access

\section{Abstract}

Objectives: Severe protein energy malnutrition results in muscle wasting and loss of subcutaneous tissue and has serious implications for health, recovery from illness or surgery, and hospital costs; however this condition is often underestimated and considered as one of the aspects of aging. We measure the incidence of malnutrition and its consequences on general health, physical and mental performance in a cohort of elderly patients. Study Design: This is a cross-sectional study conducted in a geriatric inpatient unit. Three hundred patients admitted to the clinic who fulfilled the inclusion criteria were enrolled. Main Outcome Measures: Nutritional status was evaluated by Mini Nutritional Assessment (MNA) questionnaire, macro and micronutrients intake, anthropometric measures and biochemical parameters. Physical and mental performances were recorded by questionnaires. Muscular strength was measured by a hand dynamometer and clinical outcomes were recorded. Results: Patients with poor nutritional status have lower physical and mental performance as respect to well nourished patients. Undernourished patients have longer hospitalization and worst outcomes. We observe a high prevalence of severe hypovitaminosis $D$ and the intake of various micronutrients was severely unbalanced. The incidence of malnutrition was $25 \%$ (75 patients); $39 \%$ (119 patients) were at risk of malnutrition. MNA was inversely related with the length of hospital stay $(R=-0.25, p=0.012)$ and with Geriatric Depression Scale (GDS) (R $=-0.56, p=0.000)$, whereas directly related with cognitive performance measured through Mini Mental State Examination (MMSE) $(R=0.5, p=0.000)$ and hand grip strength $(R=0.35, p=0.000)$. Conclusions: Malnutrition significantly reduced quality of life, physical and mental performance and worsened patients' prognosis.

\footnotetext{
"Corresponding author.
} 


\section{Keywords}

\section{Malnutrition, Quality of Life, Muscular Strength, Aging}

\section{Introduction}

Malnutrition is a disorder of nutritional status due to reduced nutrient intake or impaired metabolism; it comprises a broad spectrum of clinical conditions from mild to very severe [1]. Malnutrition has been frequently described among the elderly in hospital patients [1]-[3]; this condition is often underestimated and considered as one of the aspects of aging.

Incidence of malnutrition in hospitalized patients ranges between 20\% and 50\% [1]-[3], and in community dwelling elderly between $5 \%$ and $10 \%$ [4].

Severe protein energy malnutrition has serious implications for health, recovery from illness or surgery, and hospital costs [3] [5]-[8].

Elderly people are at high risk of malnutrition; a variety of factors including sensory losses, anorexia, chewing and swallowing problems, chronic and acute diseases and multi-medication may compromise dietary intake and lead to nutritional deficiencies and malnutrition [9] [10].

Very often protein-caloric malnutrition presents together with inadequate micronutrient intake: the most diffuse are inadequate intake of calcium [11], vitamin D [1] and iron. Vitamin D deficiency is also attributable to lifestyle: outdoor activities and sun exposition that are generally reduced in the elderly population, furthermore vitamin D cutaneous synthesis is reduced by aging [12]. These peculiar dietary deficiencies are implied in the reduction of muscular strength [13] [14], increased risk of fractures [1] [15] [16] and chronic anaemia that often present together in the frail elderly.

The purposes of this study are to measure the incidence of protein-caloric and micronutrient malnutrition in a population of elderly patients hospitalized with acute or chronic disease recurrence in the Geriatric Unit of our hospital and to correlate malnutrition with patients' quality of life, physical and mental performance and health outcomes. We further evaluate the role of micronutrients deficiency in determining muscular force.

\section{Materials and Methods}

The study was approved by the "Clinical Study Review Committee" of our Hospital; informed consent from all the participants was obtained. We enrolled all the patients hospitalized from December 2009 to May 2011 in our unit, according to the following criteria:

\subsection{Inclusion Criteria}

Mini Mental State Examination (MMSE) $\geq 18$;

Community dwelling.

\subsection{Exclusion Criteria}

MMSE < 18;

Major chronic illness that affect nutritional status:

Severe heart failure (NYHA III-IV);

Chronic renal disease (glomerular filtration rate (Cockroft-Gault) $<30 \mathrm{ml} / \mathrm{min}$ );

Hepatic insufficiency (Child-Pugh score B-C);

Known malignancy.

Patients living in nursing homes:

Patients living in nursing homes were excluded because we assume their dietary intake and lifestyle may be altered compared to general elderly population, and hence overestimate the incidence of malnutrition [2] [3].

\subsection{Malnutrition Assessment}

We assessed malnutrition by Mini Nutritional Assessment (MNA) questionnaire [17]. The MNA includes 18 
items and the score is calculated using an assigned weighted score for each item. Items include questions about appetite and weight loss, mobility, recent acute illness and stress, nutritional habits and grade of dependence, perceived nutrition; moreover the score evaluates number of medications, presence of sores and anthropometric parameters. Possible final scores range from 0 to 30. Older persons with scores higher than 23.5 are classified as having a "normal" nutritional status, those with scores from 17 to 23 are classified as "at risk of malnutrition", and those with scores less than 16 are classified as experiencing "malnutrition" [18].

Dietary intake was recorded and calculated using the PROGEO software (Progeo s.r.l. Italy) as average weekly intake. Macro and micro-nutrients intake was recorded.

We measured blood levels of albumin, total proteins and pre-albumin, serum iron, transferrin, ferritin, serum vitamin B12 and folic acid, serum $25 \mathrm{OH}$ vitamin D, serum calcium and phosphate and level of PTH with standard methods.

Percentage of saturated transferrin was calculated with the formula: serum iron/(transferrin $\times 1.42) \times 100$.

\subsection{Anthropometric Evaluation}

In all patients we assessed body composition through the measurement of:

-Body mass index (BMI): patients were weighed with precision scale and their height was recorded with an altimeter wall, the BMI was measured as weight in $\mathrm{kg} /$ height in meters squared.

-Body fat mass through the use of a plicometre (Mahr GMBH Esslingen), the Pollock, Schmidt and Jackson's formula on three sites (triceps, subscapular and abdomen) was applied [19]-[21].

-Brachial circumference, waist/hip ratio [22] were recorded, the brachial measure was taken with patients standing at average distance between the top of the shoulder and the elbow with the arm relaxed along the side.

\subsection{Measurements of Performance}

In order to evaluate how malnutrition affects physical and psychological performances we measured:

-Muscular force through the measurements of hand grip strength of dominant hand, by a hydraulic hand dynamometer (MSD, Europe) [23]. In each evaluation, three attempts of maximal isometric effort held for 6 seconds and with a range of 2 minutes between them were conducted in order to avoid accumulated muscle fatigue. The average of the three assessments was recorded. In all assessments, a standardized position was adopted: the subject remained comfortably seated, shoulder adducted with no rotation: forearm flexed to 90 degrees and in neutral position, wrist position ranging from 0 and 30 degrees of extension was used. The patients received verbal guidance and encouragement "one, two, three, NOW! ... STRENGTH! ... STRENGTH! ... STRENGTH! ... THAT'S IT! ... RELAX...” issuing in a vigorously manner, in order to guarantee a maximum force during the 6 seconds of each test.

After each attempt, results were recorded for later statistical analysis.

-The Activities of Daily Living (ADL) by a validated questionnaire.

-To evaluate mood level we used the geriatric depression scale (GDS), GDS higher 7 defines depression $\operatorname{mood}[24]$.

-Patient's health perception was evaluated through the SF 36 questionnaire [25] and the osteo-articular pain was measured by a Verbal Numeric Scale (VNS: $0=$ no pain and $10=$ maximum pain).

\subsection{Health Outcomes}

We recorded the presence of pressure and vascular sores, the length of hospitalization and the discharge mode.

\subsection{Statistical Analysis}

The normal distribution of measured parameter was determined with kurtosis.

Patients were considered as undernourished, at risk of malnutrition and with normal nutritional status according to MNA; these categories were compared by means of one way ANOVA with Bonferroni post hoc test for continuous Gaussian variables, by Kuskal-Wallis test for continuous non-Gaussian variables or by chi square test for non continuous variables after weighting cases for age.

MNA was correlated with clinical outcome and performance status with partial correlation after correction for age and hand grip strength. 
Microelements intake was correlated to hand grip strength with Pearson R Test for continuous Gaussian variables and Rho Spearman for non-Gaussian variables, correction for MNA was performed. Macronutrients intake was correlated to hand grip strength after correction for age.

The SPSS 20.0 software package was used to process the data with $\mathrm{p}<0.05$ as the significance cut-off.

\section{Results}

Three hundred patients (age $80 \pm 6$ yrs) were enrolled in the study (136 males and 164 females): males were on average younger than females ( $79 \pm 7$ yrs vs $82 \pm 7, \mathrm{p}=0.003)$.

The incidence of malnutrition according to MNA was 25\% (75 patients), 39\% (119 patients) were at risk of malnutrition, whereas 36\% (106 patients) did not have nutritional problems.

Malnourished patients were older, more likely women, had a lower BMI, and lower body fat percentage, worst nutritional index, as shown in Table 1; these data confirm the good ability of MNA to detect malnutrition as previously demonstrated [18].

\subsection{Malnutrition Influences Health Outcomes and Physical Performance}

As undernourished patients were older the analyses of outcomes and performances amongst MNA categories was corrected for age. Our results show that the performance status, articular pain, presence of vascular or pressure sores, length of hospital stay and mortality were adversely influenced by malnutrition and risk of malnutrition regardless of age.

Patients with worst nutritional status perform poorlyas respect to patients at risk of malnutrition for all the analysed variables, articular pain was significantly higher in patients both undernourished and at risk of malnutrition as respect to subjects with normal nutritional status (Table 3).

Table 1. Patients' characteristic according to nutritional status. Means and standard deviations are shown for Gaussian variables, median and $25^{\text {th }}, 75^{\text {th }}$ percentiles are shown for non Gaussian variables (indicated by ${ }^{*}$ ), percentages are shown for non continuous variables. p values are shown.

\begin{tabular}{|c|c|c|c|c|}
\hline & Malnourished (75) & At risk of malnutrition (119) & Normal nutritional status (106) & $\mathrm{p}$ \\
\hline Age (yrs) & $85 \pm 7$ & $80 \pm 7$ & $78 \pm 7$ & 0.000 \\
\hline Female (\%) (number) & $68(51)$ & $49.6(59)$ & $51(54)$ & 0.027 \\
\hline $\mathrm{BMI}$ & $21.5(20-23.5)$ & $24(21.8-26.8)$ & $25.4(24.4-27.8)$ & $0.000^{*}$ \\
\hline Fat mass (\%) & $28.1 \pm 6.8$ & $31.15 \pm 7.7$ & $33.7 \pm 7.1$ & 0.000 \\
\hline Brachial circumference $(\mathrm{cm})^{*}$ & $23.5(21-26)$ & $26.5(25-28)$ & $28(26-29)$ & 0.000 \\
\hline waist/hip ratio & $0.96 \pm 0.07$ & $0.99 \pm 0.07$ & $0.99 \pm 0.06$ & 0.004 \\
\hline Pre-albumin (mg/dL) & $16.34 \pm 6.4$ & $18.71 \pm 7.3$ & $18.7 \pm 6.14$ & 0.033 \\
\hline Albumin (g/dL) & $3.38 \pm 0.44$ & $3.49 \pm 0.47$ & $3.6 \pm 0.38$ & 0.004 \\
\hline Total protein $(\mathrm{g} / \mathrm{dL})^{*}$ & $6(5.7-6.6)$ & $6.2(5.8-6.6)$ & $6.2(5.9-6.7)$ & NS \\
\hline $\operatorname{Iron}(\mu \mathrm{g} / \mathrm{dL})^{*}$ & $36(31-44)$ & $38(31-52)$ & $40(30-52.3)$ & NS \\
\hline Ferritin $(\mathrm{ng} / \mathrm{mL})^{*}$ & $110(68-212)$ & $111(61-220)$ & $116(68.3-191)$ & NS \\
\hline Transferrin (mg/dL) & $231.7 \pm 83$ & $240.9 \pm 76$ & $262.2 \pm 74$ & 0.022 \\
\hline Saturated transferrin (\%) ${ }^{*}$ & $3.1(2.5-4.3)$ & $3.2(2.7-4.3)$ & $3.6(2.9-4.4)$ & NS \\
\hline $25 \mathrm{OH}$ vitamin $\mathrm{D}(\mathrm{nMol} / \mathrm{L})^{*}$ & $11.5(3.8-18)$ & $11.2(7.8-18)$ & $12.95(8.1-20.2)$ & NS \\
\hline Serum calcium (mMol/L) ${ }^{*}$ & $2.15(2.07-2.27)$ & $2.17(2.11-2.24)$ & $2.2(2.1-2.29)$ & NS \\
\hline Serum phosphate $(\mathrm{mMol} / \mathrm{L})^{*}$ & $0.92(0.81-1.02)$ & $0.95(0.88-1.08)$ & $0.98(0.9-1.1)$ & 0.02 \\
\hline PTH $(\mathrm{pg} / \mathrm{mL})^{*}$ & $16.3(10.2-42)$ & $19.3(10.5-34)$ & $19(10.5-32)$ & NS \\
\hline
\end{tabular}


As regards the perceived health status, undernourished patients had worst perceived physical performances and worst mood level (Figure 1).

Malnutrition significantly influences discharge mode independently from age: undernourished patients showed higher risk of death and were more likely to be discharged in a nursing home (Figure 2).

In order to evaluate if the severity of malnutrition influences the analysed variables we carried on partial correlations between MNA and the analysed variables after adjustment for age; MNA was inversely related with the length of hospital stay $(\mathrm{R}=-0.25, \mathrm{p}=0.012)$, with GDS $(\mathrm{R}=-0.56, \mathrm{p}=0.000)$ and with articular pain $(\mathrm{R}=$ $-0.21, \mathrm{p}=0.041)$, whereas directly related with MMSE $(\mathrm{R}=0.5, \mathrm{p}=0.000)$ and hand grip strength $(\mathrm{R}=0.35, \mathrm{p}$ $=0.000)$.

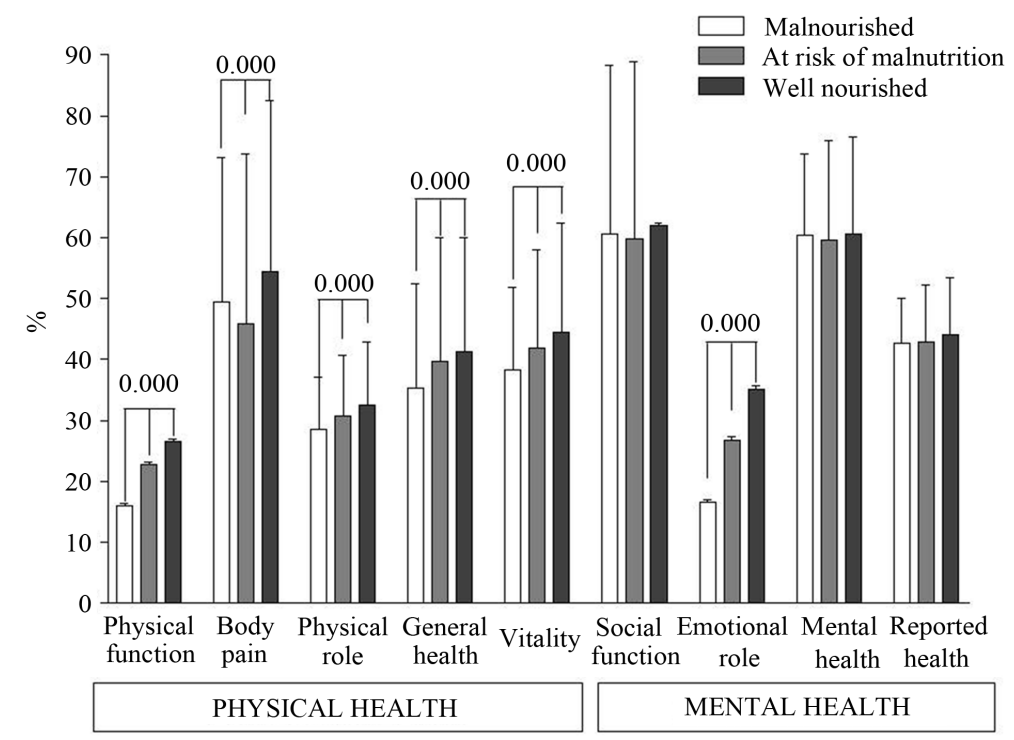

Figure 1. Malnutrition influences perceived quality of life. Bars show mean and standard deviation for each item of the SF 36 questionnaire amongst undernourished, at risk of malnutrition and patients with normal nutritional status, the items are grouped into physical and mental performances. p values calculated with one way ANOVA after weighting cases for age are shown.

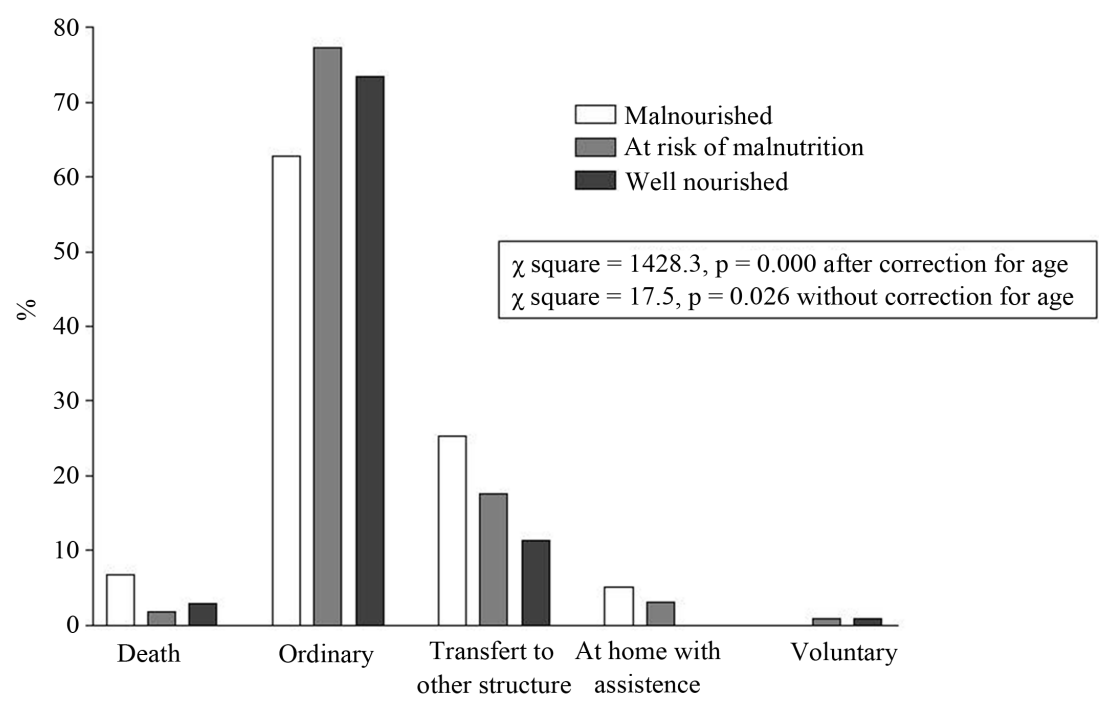

Figure 2. Malnutrition influences discharge mode. Bars show the discharge mode in percentage according to nutritional status. $\mathrm{p}$ and $\chi$ square values calculated with $\chi$ square test with or without correction for age are shown. 


\subsection{Malnutrition and Micronutrients Deficiency}

As regards dietary intake it is interesting to point out that the main differences in dietary intake amongst different MNA categories were the caloric intake and the micro-nutrient intake, whereas there was no significant difference in the distribution of macronutrients (Table 2).

We analysed the intake of various micronutrients (minerals and vitamins): it was significantly lower in malnourished patients as shown in Table 2. The calcium and vitamin D intake were greatly below the recommended threshold in all the categories, whereas the iron intake was below the recommended level only in undernourished

Table 2. Macro and micronutrients daily intake in malnourished, at risk for malnourishment and well nourished patients. Means and standard deviations are shown for Gaussian variables, mean \pm SD, median and $25^{\text {th }}, 75^{\text {th }}$ percentiles are shown for non Gaussian variables (indicated by ${ }^{*}$ ), percentages are shown for non continuous variables. p values were calculated by one way ANOVA for Gaussian variables, by Kruskal Wallis test for non-Gaussian variables and by $\chi$ square test for non-continuous variables.

\begin{tabular}{ccccc}
\hline & \multicolumn{3}{c}{ Macronutrients } & \\
\hline & Malnourished (75) & At risk of malnutrition (119) & Normal nutritional status (106) & p \\
\hline Caloric intake (Kcal/day) & $1345.5 \pm 328.3$ & $1596.9 \pm 376$ & $1717 \pm 353$ & 0.000 \\
Protein intake (g/Kg weight) & $1 \pm 0.27$ & $1 \pm 0.25$ & $1 \pm 0.18$ & NS \\
Carbohydrate intake (g/Kg weight) & $3.6 \pm 1$ & $3.4 \pm 0.9$ & $3.4 \pm 0.8$ & NS \\
Lipid intake (g/Kg weight) & $0.75 \pm 0.23$ & $0.69 \pm 0.24$ & $0.71 \pm 0.19$ & NS \\
\hline
\end{tabular}

\begin{tabular}{|c|c|c|c|c|}
\hline \multicolumn{5}{|c|}{ Microelements } \\
\hline & Malnourished (75) & At risk of malnutrition (119) & Normal nutritional status (106) & $\mathrm{p}$ \\
\hline Copper* (mg) & $1.2(1-1.4)$ & $1.4(1.2-1.6)$ & $1.4(1.2-1.6)$ & 0.000 \\
\hline Pantotenic acid* (mg) & $2.8(2.4-3.2)$ & $3.3(2.7-4.1)$ & $3.45(3.07-3.92)$ & 0.000 \\
\hline Biotin $^{*}$ (mcg) & $22.2(17.2-27.1)$ & $27.9(21.4-33.1)$ & $29(24.75$ - 33.92) & 0.000 \\
\hline Vitamin $A^{*}$ (mcg) & 867.5 (600.1 - 1 209) & $1064.6(808.4-1454.9)$ & 1091.55 (916.8 - 1359.17) & 0.014 \\
\hline Vitamn B1 ${ }^{*}$ (mg) & $0.8(0.6-0.9)$ & $0.8(0.7-1.2)$ & $0.9(0.7-1.1)$ & 0.010 \\
\hline Vitamin $D^{*}$ (mcg) & $2.6(1.5-4.2)$ & $3.3(1.8-4.6)$ & $3.5(2.17-4.72)$ & 0.019 \\
\hline Calcium (mg) & $687.21 \pm 236.82$ & $750.16 \pm 269.55$ & $816.76 \pm 261.64$ & 0.004 \\
\hline Chrome (mg) & $148.03 \pm 53.76$ & $204.46 \pm 83.61$ & $233.4 \pm 86.77$ & 0.000 \\
\hline Iron (mg) & $7.86 \pm 2.91$ & $10.2 \pm 3.33$ & $10.52 \pm 2.71$ & 0.000 \\
\hline Phosphate (mg) & $924.44 \pm 255.52$ & $1081.59 \pm 282.87$ & $1151.69 \pm 284.51$ & 0.000 \\
\hline Magnesium (mg) & $219.79 \pm 67.57$ & $266.84 \pm 68.52$ & $276.34 \pm 67.78$ & 0.000 \\
\hline Manganese (mg) & $1.97 \pm 0.85$ & $2.52 \pm 0.89$ & $2.63 \pm 1.06$ & 0.000 \\
\hline Molybdenum (mcg) & $27.44 \pm 14.71$ & $34.28 \pm 17.25$ & $34.22 \pm 15.44$ & 0.007 \\
\hline Potassium (mg) & $2119.73 \pm 566.86$ & $2516.96 \pm 642.33$ & $2647.77 \pm 575.99$ & 0.000 \\
\hline Selenium (mcg) & $43.77 \pm 20.28$ & $50.72 \pm 22.86$ & $55.17 \pm 26.26$ & 0.006 \\
\hline Sodium (mg) & $1675.68 \pm 1050.97$ & $2010.68 \pm 1238.47$ & $2104.67 \pm 1246.49$ & NS \\
\hline Zinc (mg) & $7.93 \pm 2.63$ & $8.98 \pm 2.67$ & $9.72 \pm 2.61$ & 0.000 \\
\hline Folic acid (mcg) & $164.34 \pm 64.93$ & $224.36 \pm 71.67$ & $230.55 \pm 61.66$ & 0.000 \\
\hline Niacine (mg) & $12.43 \pm 4.09$ & $14.61 \pm 4.88$ & $14.73 \pm 3.79$ & 0.001 \\
\hline
\end{tabular}


patients. Levels of serum $25 \mathrm{OH}$ vitamin D were defined as severe hypovitaminosis $(<50 \mathrm{nMol} / \mathrm{L})$, vitamin D insufficiency (between 50 and $75 \mathrm{nMol} / \mathrm{L}$ ) and acceptable ( $>75 \mathrm{nMol} / \mathrm{L}$ ), according to Bischoff-Ferrari [26]. In our population serum levels of $25 \mathrm{OH}$ vitamin D showed 99.7\% (299) of patients with hypovitaminosis, none had vitamin D insufficiency ( $0 \%$ ) and only 1 patient $(0.3 \%)$ had acceptable vitamin D levels.

In order to evaluate the role played by micronutrient deficiency in determining muscular strength, we analysed the correlation between these variables after correction for MNA. The intake of iron $(\mathrm{R}=0.234, \mathrm{p}=$ $0.014)$, magnesium $(R=0.221, p=0.027)$, manganese $(R=0.202, p=0.034)$ and vitamin $E(R=0.292, p=$ 0.002 ) were directly although weakly correlated to grip strength even after correction for MNA. These data suggest a direct effect of these nutrients rather than general malnutrition in muscular force. The macronutrients intake pro Kilogram does not correlate with muscular force after correction for age.

\section{Discussion}

Criteria used to define malnutrition vary greatly amongst the studies; here we used MNA [18], and confirmed the data obtained using anthropometric measurements, biochemical parameters and dietary intake questionnaire in a cohort of patients being hospitalized and coming from their home. A wide range of pathological conditions could influence nutritional status in the elderly, here we report data obtained from a population with no indication of major acute or chronic illness that affect nutritional status: patients with known malignancies, severe heart failure, severe renal impairment (clearance $<30 \mathrm{ml} / \mathrm{min}$ ) or hepatic cirrhosis were excluded.

The incidence of malnutrition and risk of malnutrition is considerably high (64.7\%) as compared to other in hospital patients' studies: this could be due to the different methods used to asses this condition.

This study shows that undernourished patients have a normal BMI and this could lead to under diagnosis of their condition as BMI is the most frequently used parameter for nutritional assessment (see Pauly et al. for a review [10]), whereas MNA considered BMI values together with other features to define malnutrition. We also show that the main difference in dietary intake amongst MNA categories is the caloric intake, significantly reduced in undernourished patients, whereas the intake of macronutrients as percentage of caloric intake was not significantly different in the three groups.

Some studies suggest that hand grip strength is an independent predictor of performance status and health outcomes [23] [27]. Loss in muscle function is an early sign of protein under-nutrition since muscles are the body's largest protein reserve, and hand grip is a validated method for the evaluation of voluntary muscle strength.

Vitamin A, B1 and D intake is significantly lower in malnourished patients, vitamin D intake was significantly different in the three groups, but all the patients were affected by hypovitaminosis $\mathrm{D}$ and the vitamin $\mathrm{D}$ intake was greatly below the RDA regardless MNA. The reduction in iron intake is evident by the increased level of saturated transferrin, whereas the reduction in vitamin D and calcium intake is reflected by reduced level of serum phosphate in undernourished patients, even if phosphate remains in the normal range this is a clear index of augmented PTH. This datum confirms our previous work on postmenopausal osteoporotic women [28] in which we found a significant reduction in phosphate serum level directly related to PTH levels. In this study we cannot measure an increase in PTH; this could be due to assays problems.

Several micronutrient intakes were severely unbalanced by malnutrition and magnesium, manganese and vitamin $\mathrm{E}$ assumption are directly correlated with muscle performance regardless to MNA. Vitamin E and vitamin $\mathrm{C}$ have a role in scavenging reactive oxygen species (ROS), component of the stress response that may contribute to muscle damage during exercise. Vitamin $\mathrm{E}$ is an antioxidant compound and may have a role in preventing muscle damage by scavenging ROS [29]. On the other hand, magnesium is required for energy production pathway in mitochondria and ATP production, and also acts as an antioxidant against free radical damage of the mitochondria [30]. We did not observe any correlation between Vitamin D intake and muscular performance. Even though it is well known that hypovitaminosis D can influence physical performance [13] [14] [31]-[33], in our population almost all the patients have hypovitaminosis $\mathrm{D}$ and we could not compare our patients with a control population with normal Vitamin D levels.

Malnutrition influences physical and mental performance regardless of age also in patients not yet malnourished, but at risk for malnutrition (Table 3). In particular malnutrition significantly influences the depression mood and the mental performance, even in absence of dementia; malnutrition also reduced the perceived mental health of the patients and is significantly related with loss of independency in the ADL. 
Table 3. Malnutrition and patients performance and health outcomes. Comparison between patients found undernourished, at risk of malnutrition and with normal nutritional status for physical and mental performance and clinical outcomes after correction for age. Means and standard deviations are shown for continuous Gaussian variables (indicated by ${ }^{*}$ ), median and $25^{\text {th }}$, $75^{\text {th }}$ percentiles are shown for continuous non Gaussian variables, percentages are shown for non continuous variables. $p$ values are shown.

\begin{tabular}{|c|c|c|c|c|}
\hline & Malnourished (75) & At risk of malnutrition (119) & Normal nutritional status (106) & $\mathrm{p}$ \\
\hline $\mathrm{ADL}$ & $3.98 \pm 1.9$ & $1.8 \pm 0.2$ & $0.72 \pm 0.02$ & 0.000 \\
\hline GDS & $7.95 \pm 3.3$ & $5.47 \pm 3.5$ & $2.99 \pm 2.5$ & 0.000 \\
\hline MMSE & $21.2 \pm 2.9$ & $23.4 \pm 2.9$ & $24.6 \pm 2.6$ & 0.000 \\
\hline Osteo articular pain (VNS) & $4.1 \pm 2.8$ & $3.8 \pm 2.9$ & $2.7 \pm 2.0$ & 0.000 \\
\hline Hand grip strength (Kg) & $3.8 \pm 0.1$ & $13.7 \pm 9.9$ & $19.7 \pm 11.7$ & 0.000 \\
\hline Length of hospital stay (days) ${ }^{*}$ & $10(8-15)$ & $10(5-16)$ & $8(5-12)$ & 0.000 \\
\hline Death (\%) (number) & $6.7(5)$ & $1.7(2)$ & $2.8(3)$ & 0.000 \\
\hline Patients with pressure sores (\%) (number) & $28(21)$ & $5.8(7)$ & $0.9(1)$ & 0.000 \\
\hline Patients with vascular sores (\%) (number) & $9(7)$ & $11.6(14)$ & $2.8(3)$ & 0.000 \\
\hline
\end{tabular}

Undernourished patients have reduced physical performance both perceived and measured through hand grip strength. Epidemiological studies have demonstrated that low hand grip strength in healthy adults predicts increased risk of functional limitations and disability in older age as well as all-cause mortality [23] [27]. As muscle function reacts early to nutritional deprivation, hand grip strength has also become a popular marker of nutritional status [23]; in this study we confirm that hand grip strength has to be considered not an independent predictor of health outcomes, but it is strictly correlated to malnutrition. In particular loss of muscular force is due to micronutrient malnutrition rather than general reduction in caloric and macronutrient intake.

As regards health outcomes undernourished patients have a higher incidence of death during hospitalization, tend to stay longer in hospital and have higher incidence of sores. In particular we observe a higher incidence of pressure and vascular ulcers, these data confirms the literature for pressure sores, in fact it is known that nutritional intervention may accelerate the healing of these lesions [34] [35]; whereas there are no data in literature on vascular sore. These observations are important in order to suggest an early evaluation of nutritional status of elderly patients and an early intervention to reduce the effect of malnutrition on health outcomes.

Our results show that severe hypovitaminosis D is present in nearly $100 \%$ of our cohort, regardless to dietary intake and severity of malnutrition, as hypovitaminosis D has been associated with poor health outcomes and increased mortality [31] [32] [36] [37], it is important to increase physicians' attention towards this problem.

The shortcomings of this study are the limited cohort enrolled and the lack of information about muscular performance other than hand grip test. Further studies on general healthy community dwelling population may be useful to assess malnutrition incidence.

\section{Conclusion}

In conclusion we show that malnutrition has an important role in determining elderly independence, physical and mental performance and in predicting health outcomes, hence the hospital team have to pay great attention to this problem even in community dwelling elderly.

\section{Statement of Authors' Contributions to Manuscript}

PD planned the study, performed statistical analyses and wrote the draft of the manuscript.

BR, CE, MTM and DC participated in the planning of the study, enrolled the patients and collected the data, critically revised the manuscript.

VD, MR, GF and GCI participated in the planning of the study and critically revised the manuscript. All authors have read and approved the final manuscript. 


\section{Disclaimers}

None.

\section{Founding Sources}

City of Health and Science Hospital.

\section{Conflict of Interest}

None.

\section{References}

[1] Corino, A., D’Amelio, P., Gancia, R., Del Rizzo, P., Gabasio, S., Limone, P. and Isaia, G. (2007) Hypovitaminosis D in Internal Medicine Inpatients. Calcified Tissue International, 80, 76-80. http://dx.doi.org/10.1007/s00223-006-0189-x

[2] Gaskill, D., Black, L.J., Isenring, E.A., Hassall, S., Sanders, F. and Bauer, J.D. (2008) Malnutrition Prevalence and Nutrition Issues in Residential Aged Care Facilities. Australasian Journal on Ageing, 27, 189-194. http://dx.doi.org/10.1111/j.1741-6612.2008.00324.x

[3] Kaiser, M.J., Bauer, J.M., Ramsch, C., Uter, W., Guigoz, Y., Cederholm, T., Thomas, D.R., Anthony, P.S., Charlton, K.E., Maggio, M., Tsai, A.C., Vellas, B. and Sieber, C.C. (2010) Frequency of Malnutrition in Older Adults: A Multinational Perspective Using the Mini Nutritional Assessment. Journal of the American Geriatrics Society, 58, 17341738. http://dx.doi.org/10.1111/j.1532-5415.2010.03016.x

[4] McCormack, P. (1997) Undernutrition in the Elderly Population Living at Home in the Community: A Review of the Literature. Journal of Advanced Nursing, 26, 856-863. http://dx.doi.org/10.1046/j.1365-2648.1997.00415.x

[5] Loser, C. (2010) Malnutrition in Hospital: The Clinical and Economic Implications. Deutsches Ärzteblatt international, 107, 911-917.

[6] Corish, C.A. and Kennedy, N.P. (2000) Protein-Energy Undernutrition in Hospital In-Patients. British Journal of Nutrition, 83, 575-591. http://dx.doi.org/10.1017/S000711450000074X

[7] Heersink, J.T., Brown, C.J., Dimaria-Ghalili, R.A. and Locher, J.L. (2010) Undernutrition in Hospitalized Older Adults: Patterns and Correlates, Outcomes, and Opportunities for Intervention with a Focus on Processes of Care. Journal of Nutrition for the Elderly, 29, 4-41. http://dx.doi.org/10.1080/01639360903574585

[8] Milne, A.C., Potter, J., Vivanti, A. and Avenell, A. (2009) Protein and Energy Supplementation in Elderly People at Risk from Malnutrition. Cochrane Database of Systematic Reviews, 15, Article ID: CD003288.

[9] Kulnik, D. and Elmadfa, I. (2008) Assessment of the Nutritional Situation of Elderly Nursing Home Residents in Vienna. Annals of Nutrition and Metabolism, 52, 51-53. http://dx.doi.org/10.1159/000115350

[10] Pauly, L., Stehle, P. and Volkert, D. (2007) Nutritional Situation of Elderly Nursing Home Residents. Zeitschrift für Gerontologie und Geriatrie, 40, 3-12. http://dx.doi.org/10.1007/s00391-007-0430-x

[11] D’Amelio, P., Tamone, C., Pluviano, F., Di Stefano, M. and Isaia, G. (2005) Effects of Lifestyle and Risk Factors on Bone Mineral Density in a Cohort of Italian Women: Suggestion for a New Decision Rule. Calcified Tissue International, 77, 72-78. http://dx.doi.org/10.1007/s00223-004-0253-3

[12] Gilchrest, B.A. (2008) Sun Exposure and Vitamin D Sufficiency. The American Journal of Clinical Nutrition, 88, 570S-577S.

[13] Mastaglia, S.R., Seijo, M., Muzio, D., Somoza, J., Nunez, M. and Oliveri, B. (2011) Effect of Vitamin D Nutritional Status on Muscle Function and Strength in Healthy Women Aged over Sixty-Five Years. The Journal of Nutrition, health \& aging, 15, 349-354. http://dx.doi.org/10.1007/s12603-010-0287-3

[14] Dretakis, O.E., Tsatsanis, C., Fyrgadis, A., Drakopoulos, C.G., Steriopoulos, K. and Margioris, A.N. (2010) Correlation between Serum 25-Hydroxyvitamin D Levels and Quadriceps Muscle Strength in Elderly Cretans. Journal of International Medical Research, 38, 1824-1834. http://dx.doi.org/10.1177/147323001003800530

[15] Isaia, G., Giorgino, R., Rini, G.B., Bevilacqua, M., Maugeri, D. and Adami, S. (2003) Prevalence of Hypovitaminosis $\mathrm{D}$ in Elderly Women in Italy: Clinical Consequences and Risk Factors. Osteoporosis International, 14, 577-582. http://dx.doi.org/10.1007/s00198-003-1390-7

[16] Ryan, P. and Dixon, T. (2006) Prevalence of Vitamin D Inadequacy in Patients Attending a Metabolic Bone Clinic in Medway. Current Medical Research and Opinion, 22, 211-216. http://dx.doi.org/10.1185/030079906X80369

[17] Guigoz, Y., Vellas, B. and Garry, P.J. (1996) Assessing the Nutritional Status of the Elderly: The Mini Nutritional Assessment as Part of the Geriatric Evaluation. Nutrition Reviews, 54, S59-S65. 
http://dx.doi.org/10.1111/j.1753-4887.1996.tb03793.x

[18] Guigoz, Y. (2006) The Mini Nutritional Assessment (MNA) Review of the Literature-What Does It Tell Us? Journal of Nutrition Health and Aging, 10, 466-485.

[19] Durnin, J.V. and Womersley, J. (1974) Body Fat Assessed from Total Body Density and Its Estimation from Skinfold Thickness: Measurements on 481 Men and Women Aged from 16 to 72 Years. British Journal of Nutrition, 32, 77-97. http://dx.doi.org/10.1079/BJN19740060

[20] Jackson, A.S. and Pollock, M.L. (1978) Generalized Equations for Predicting Body Density of Men. British Journal of Nutrition, 40, 497-504. http://dx.doi.org/10.1079/BJN19780152

[21] Jackson, A.S., Pollock, M.L. and Ward, A. (1980) Generalized Equations for Predicting Body Density of Women. Medicine \& Science in Sports \& Exercise, 12, 175-181. http://dx.doi.org/10.1249/00005768-198023000-00009

[22] Cepeda-Valery, B., Pressman, G.S., Figueredo, V.M. and Romero-Corral, A. (2011) Impact of Obesity on Total and Cardiovascular Mortality-Fat or Fiction? Nature Reviews Cardiology, 8, 233-237.

[23] Norman, K., Stobäus, N., Gonzalez, M.C., Schulzke, J.D. and Pirlich, M. (2011) Hand Grip Strength: Outcome Predictor and Marker of Nutritional Status. Clinical Nutrition, 30, 135-142. http://dx.doi.org/10.1016/j.clnu.2010.09.010

[24] Rinaldi, P., Mecocci, P., Benedetti, C., Ercolani, S., Bregnocchi, M., Menculini, G., Catani, M., Senin, U. and Cherubini, A. (2003) Validation of the Five-Item Geriatric Depression Scale in Elderly Subjects in Three Different Settings. Journal of the American Geriatrics Society, 51, 694-698. http://dx.doi.org/10.1034/j.1600-0579.2003.00216.x

[25] Brazier, J.E., Harper, R., Jones, N.M., O’Cathain, A., Thomas, K.J., Usherwood, T. and Westlake, L. (1992) Validating the SF-36 Health Survey Questionnaire: New Outcome Measure for Primary Care. BMJ, 305, 160-164. http://dx.doi.org/10.1136/bmj.305.6846.160

[26] Bischoff-Ferrari, H. (2009) Vitamin D: What Is an Adequate Vitamin D Level and How Much Supplementation Is Necessary? Best Practice \& Research Clinical Rheumatology, 23, 789-795. http://dx.doi.org/10.1016/j.berh.2009.09.005

[27] Cooper, R., Kuh, D. and Hardy, R. (2010) Objectively Measured Physical Capability Levels and Mortality: Systematic Review and Meta-Analysis. BMJ, 341, c4467. http://dx.doi.org/10.1136/bmj.c4467

[28] D'Amelio, P., Cristofaro, M.A., Tamone, C., Morra, E., Di Bella, S., Isaia, G., Grimaldi, A., Gennero, L., Gariboldi, A., Ponzetto, A., Pescarmona, G.P. and Isaia, G.C. (2008) Role of Iron Metabolism and Oxidative Damage in Postmenopausal Bone Loss. Bone, 43, 1010-1015. http://dx.doi.org/10.1016/j.bone.2008.08.107

[29] McGinley, C., Shafat, A. and Donnelly, A.E. (2009) Does Antioxidant Vitamin Supplementation Protect against Muscle Damage? Sports Medicine, 39, 1011-1032. http://dx.doi.org/10.2165/11317890-000000000-00000

[30] Barbagallo, M. and Dominguez, L.J. (2010) Magnesium and Aging. Current Pharmaceutical Design, 16, 832-939. http://dx.doi.org/10.2174/138161210790883679

[31] Anand, S., Kaysen, G.A., Chertow, G.M., Johansen, K.L., Grimes, B., Dalrymple, L.S. and Kurella Tamura, M. (2011) Vitamin D Deficiency, Self-Reported Physical Activity and Health-Related Quality of Life: The Comprehensive Dialysis Study. Nephrology Dialysis Transplantation, 26, 3683-3688.

[32] Bjelakovic, G., Gluud, L.L., Nikolova, D., Whitfield, K., Wetterslev, J., Simonetti, R.G., Bjelakovic, M. and Gluud, C. (2011) Vitamin D Supplementation for Prevention of Mortality in Adults. Cochrane Database of Systematic Reviews, Published Online.

[33] Muir, S.W. and Montero-Odasso, M. (2011) Effect of Vitamin D Supplementation on Muscle Strength, Gait and Balance in Older Adults: A Systematic Review and Meta-Analysis. Journal of the American Geriatrics Society, 59, 22912300. http://dx.doi.org/10.1111/j.1532-5415.2011.03733.x

[34] Ohura, T., Nakajo, T., Okada, S., Omura, K. and Adachi, K. (2011) Evaluation of Effects of Nutrition Intervention on Healing of Pressure Ulcers and Nutritional States (Randomized Controlled Trial). Wound Repair Regeneration, 19, 330-336. http://dx.doi.org/10.1111/j.1524-475X.2011.00691.x

[35] Roosen, K., Fulbrook, P. and Nowicki, T. (2010) Pressure Injury Prevention: Continence, Skin Hygiene and Nutrition Management. Australian Nursing Journal, 18, 31-34.

[36] Autier, P. and Gandini, S. (2007) Vitamin D Supplementation and Total Mortality: A Meta-Analysis of Randomized Controlled Trials. Archives of Internal Medicine, 167, 1730-1737. http://dx.doi.org/10.1001/archinte.167.16.1730

[37] Holick, M.F. (2005) The Vitamin D Epidemic and Its Health Consequences. Journal of Nutrition, 135, 2739S-2748S. 


\section{Abbreviations}

MMSE: Mini Mental State Examination NYHA: New York Heart Association MNA: Mini Nutritional Assessment

PTH: Parathyroid Hormone

BMI: Body Mass Index

ADL: Activities of Daily Living

GDS: Geriatric Depression Scale

VNS: Verbal Numeric Scale

ROS: Reactive Oxygen Species

ATP: Adenosine triphosphate

RDA: Recommended Daily Allowance 
Scientific Research Publishing (SCIRP) is one of the largest Open Access journal publishers. It is currently publishing more than 200 open access, online, peer-reviewed journals covering a wide range of academic disciplines. SCIRP serves the worldwide academic communities and contributes to the progress and application of science with its publication.

Other selected journals from SCIRP are listed as below. Submit your manuscript to us via either submit@scirp.org or Online Submission Portal.
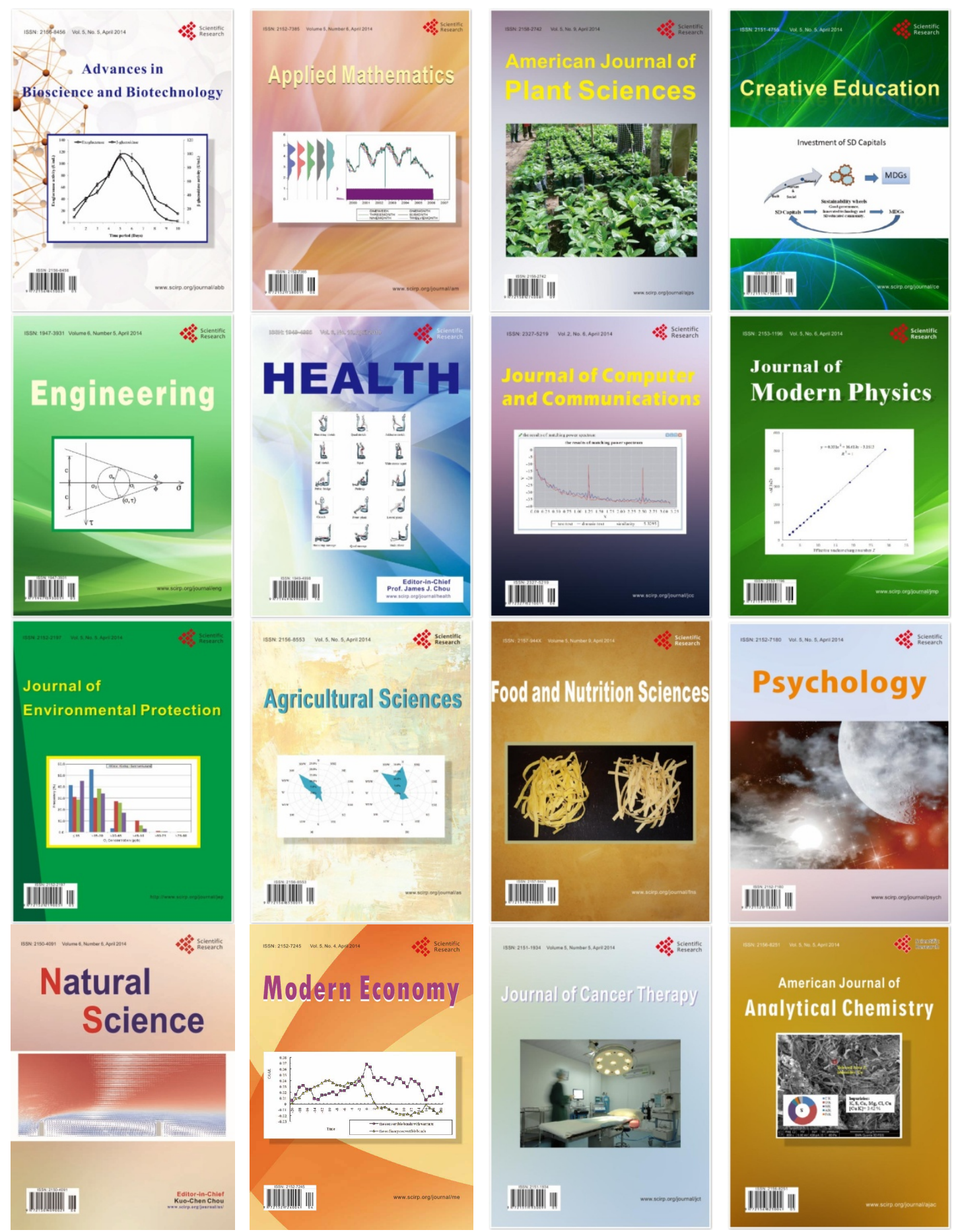